\title{
DOCUMENTO, HISTÓRIA E MEMÓRIA: A IMPORTÂNCIA DA PRESERVAÇÃO DO PATRIMÔNIO DOCUMENTAL PARA O ACESSO À INFORMAÇÃO
}

\author{
DOCUMENTO, HISTORIA Y MEMORIA: LA IMPORTANCIA \\ DE LA PRESERVACIÓN DEL PATRIMONIO DOCUMENTAL \\ PARA EL ACCESO A LA INFORMACIÓN
}

\begin{abstract}
Franciele Merlo - franciele.merlo@unila.edu.br Mestranda do Programa de Pós-Graduação Profissionalizante em

Patrimônio Cultural da Universidade Federal de Santa Maria

(PPGPPC/UFSM).
\end{abstract}

Glaucia Vieira Ramos Konrad - glaucia-k@uol.com.br Doutora em História pela Universidade Estadual de Campinas (UNICAMP). Professora de Arquivologia da Universidade Federal de Santa Maria (UFSM).

\section{RESUMO}

Introdução: A História é registrada em documentos que formam um conjunto: o patrimônio documental.

Objetivo: Este estudo tem por finalidade identificar a importância da preservação do patrimônio documental em meio à relação documento, história e memória, com vistas ao acesso à informação.

Metodologia: Do ponto de vista dos procedimentos metodológicos utilizados, trata-se de uma pesquisa bibliográfica. Assim, delimitou-se o uso de materiais publicados em livros, periódicos ou internet.

Resultados: No Brasil, a Constituição Federal de 1988 definiu os documentos públicos como patrimônio cultural do país. Esse patrimônio constitui a memória da sociedade; portanto é preciso preservá-lo para que os cidadãos brasileiros possam acessá-lo quando necessário. O direito de acesso, previsto constitucionalmente, foi regulamentado pela Lei de Acesso à Informação.

Conclusões: a lei de acesso é considerada um marco para a sociedade brasileira exercer seus direitos. $O$ intuito da preservação do patrimônio documental é possibilitar aos cidadãos 
o acesso à memória para construir sua identidade. A relação documento, história e memória é pouco abordada por pesquisadores brasileiros, sob o ponto de vista da necessidade de preservação do patrimônio documental visando ao direito da sociedade de acesso à informação. Desta maneira, instiga-se um maior desdobramento acerca do tema apresentado.

Palavras-chave: Documento. História. Memória. Patrimônio Documental. Acesso à Informação.

\section{INTRODUÇÃO}

O registro da história e da memória humana se dá, atualmente e em grande parte, por meio dos documentos gerados pelas atividades desenvolvidas por determinada organização, pessoa ou família. Esses registros, postos de maneira orgânica, passam a ser rica fonte de informação. Porém, para que constituam uma pesquisa histórica, é preciso que estejam acessíveis, a qualquer tempo, aos interessados, sejam pesquisadores ou a sociedade em geral.

As construções historiográficas muitas vezes necessitam de informação primária, ou seja, precisam ser retiradas em suas fontes originais: os documentos de arquivo. Mas, o que seria de uma sociedade, hoje, sem seus documentos? Os documentos são a essência de uma organização, a memória de uma sociedade.

Deste modo, o estudo pretende colocar em evidência a importância da preservação do patrimônio documental na relação documento-história-memória, visando ao acesso à informação. Do ponto de vista dos procedimentos metodológicos utilizados na elaboração deste artigo, delimitando-se ao uso de materiais publicados em livros, periódicos, ou internet, de acordo com Silva e Menezes (2001), considera-se uma pesquisa bibliográfica. Assim, com o referencial conceitual apresentado, busca-se elaborar uma construção teórica acerca do tema.

As demandas intelectual e social crescem e se sobrepõem às políticas de acesso, as quais devem ser constantemente revistas, à medida que a sociedade se desenvolve e apresenta novas necessidades. $E$, não sendo estática, compete ao Estado promover os meios para atendê-la, uma vez que é um direito fundamental assegurado pela Constituição Federal do Brasil. 
Tratou-se de articular, em linhas gerais, conceitos imprescindíveis ao entendimento do tema abordado, remetendo a uma reflexão sobre a relevância do assunto.

\section{DOCUMENTO, HISTÓRIA E MEMÓRIA: ANALOGIAS NA CONSTRUÇÃO DO ACESSO AO PATRIMÔNIO DOCUMENTAL}

Neste tópico são apresentadas as principais questões conceituais, as quais situam o estudo da temática abordada. Os conceitos aqui expostos norteiam as discussões, embasando a presente pesquisa.

\subsection{Os documentos de arquivo e a preservação de um patrimônio}

Antes do advento da escrita, o homem já registrava suas rotinas com desenhos e símbolos. De acordo com Richter, Garcia e Penna (2004, p. 25), o desenvolvimento dos suportes da escrita se deu da seguinte forma: "pedra, tabletes de argila, tabuinhas de madeira, papiro, pergaminho, até o papel e documentos digitais". Por mais que a evolução desses suportes tenha tornado um a um de seus antecessores obsoletos, é inegável observar que, teoricamente, o conteúdo informacional permanece e continua a ser fonte de informação.

Assim, desde que o homem passou a registrar suas atividades e pensamentos, aos poucos foi imprescindível adotar uma forma de armazenamento, o que deu origem aos arquivos. De acordo com Paes (2007), a palavra arquivo não tem sua origem definida; podendo ter nascido na Antiga Grécia como arché e, posteriormente, evoluiu para archeion, que significa "local de guarda e depósito de documentos" (PAES, 2007, p. 19). O arquivo nada mais é que um conjunto documental gerado por uma instituição pública ou privada no decorrer de suas funções (ARQUIVO NACIONAL, 2005). Paes (2007) acredita que o termo arquivo teria a origem latina, da palavra archivum.

Toda organização, pessoa e família necessitam de documentos para registrar bem como comprovar sua existência e suas atividades. Para o Arquivo Nacional (2005, p. 73), documento é: "Unidade de registro de informações, qualquer que seja o suporte [...]". Neste contexto, cabe destacar também o conceito de documentos de arquivo, que, para Bellotto "São aqueles que depois do trâmite dentro da ação que 
justificou sua criação foram recolhidos a arquivos passando pelas diversas fases do ciclo vital dos documentos" (BELLOTTO, 2006, p. 272). Sendo assim, o documento que foi produzido como resultado de certa atividade dentro de seu organismo produtor faz parte de um conjunto de mesma proveniência, o que o torna um documento de arquivo.

De acordo com o Arquivo Nacional (2011), o fator determinante que confere a um documento a sua condição de documento arquivístico é que ele faça parte de um conjunto orgânico e cumpra uma determinada função ao ser produzido; desta forma, qualquer ação ou acontecimento que se deve comprovar precisa da produção de um documento.

Indolfo destaca a importância dos documentos e dos registros para a humanidade:

O documento ou, ainda, a informação registrada, sempre foi 0 instrumento de base do registro das ações de todas as administrações, ao longo de sua produção e utilização, pelas mais diversas sociedades e civilizações, épocas e regimes. Entretanto, basta reconhecer que os documentos serviram e servem tanto para a comprovação dos direitos e para o exercício do poder, como para o registro da memória (INDOLFO, 2007, p. 29).

Sob uma perspectiva histórica, Le Goff (2012) menciona que no século XVIII foram criados os depósitos centrais de arquivo, e destaca as instituições fundadas na Europa, com a finalidade de armazenar documentos. É válido salientar que a França foi, a partir de 1789 - início da Revolução Francesa - referência na guarda de documentos públicos e, consequentemente, na constituição de uma instituição de cunho arquivístico, a qual foi chamada de Arquivo Nacional, criado posteriormente. Esse arquivo passou a reunir documentos considerados importantes para aquele período de transição entre "uma antiga sociedade e para o estabelecimento de uma nova." (SCHELLENBERG, 2006, p. 27). Nesse momento foi aprovado o "decreto de 25 de junho de 1794, que ordena a publicidade dos arquivos, abre uma nova fase, a da pública disponibilidade dos documentos da memória nacional" (LE GOFF, 2012, p. 444). Essa relevante mudança foi significativa também para o Estado assumir a responsabilidade pela centralização e conservação do acervo e, principalmente, para permitir a sociedade o acesso aos documentos sob sua custódia. Assim, tal medida se tornou um importante marco histórico, o de acesso aos documentos públicos. 
Diante disso, é perceptível a necessidade da preservação da documentação armazenada nos arquivos, uma vez que os documentos públicos podem e devem ser acessíveis à sociedade. Porém, observa-se que, da produção do documento pelos organismos públicos até o acesso à informação propriamente dito, é imprescindível a intervenção do Estado no que se refere à organização e salvaguarda, para, posteriormente, tornar o acervo acessível. Desta forma, neste país, a Constituição da República Federativa do Brasil de 1988 estabelece em seu Art. 23 que:

É competência comum da União, dos Estados, do Distrito Federal e dos Municípios: [...] III - proteger os documentos, as obras e outros bens de valor histórico, artístico e cultural, os monumentos, as paisagens naturais notáveis e os sítios arqueológicos; [...] (BRASIL, 1988, p. 18).

A Lei 8.159, de 08 de janeiro de 1991, a qual dispõe sobre os arquivos públicos e privados, promulga que: "É dever do Poder Público a gestão documental e a proteção especial a documentos de arquivos, como instrumento de apoio à administração, à cultura, ao desenvolvimento científico e como elementos de prova e informação." (BRASIL, 1991, p. 1). Consequentemente, o artigo citado evidencia a responsabilidade do Estado, atualmente, no que se refere à importância dada a proteção do Patrimônio documental do País, cabendo à administração pública proporcionar a preservação deste bem público.

Castro (2008, p. 64) cita que a Constituição Federal de 1934 faz menção à proteção dos bens patrimoniais artísticos e históricos do país, defendendo que "a noção de patrimônio histórico e artístico nacional é referida pela primeira vez (embora não exatamente com essa denominação), como sendo objeto de proteção obrigatória por parte do poder público" e aborda o texto original da Constituição, conforme o art. 10: "Compete concorrentemente à União e aos Estados: (...) III proteger as belezas naturais e os monumentos de valor histórico ou artístico [...]" (BRASIL, 1934 apud CASTRO, 2008, p. 64).

Posteriormente, a Constituição de 1988 toma o documento como um dos elementos que compõem o Patrimônio Cultural brasileiro, como exposto no Art. 216: 
Constituem patrimônio cultural brasileiro os bens de natureza material e imaterial, tomados individualmente ou em conjunto, portadores de referência à identidade, à ação, à memória dos diferentes grupos formadores da sociedade brasileira, nos quais se incluem:

I - as formas de expressão;

II - os modos de criar, fazer e viver;

III - as criações científicas, artísticas e tecnológicas;

IV - as obras, objetos, documentos, edificações e demais espaços destinados às manifestações artístico-culturais;

V - os conjuntos urbanos e sítios de valor histórico, paisagístico, artístico, arqueológico, paleontológico, ecológico e científico (BRASIL, 1988, p. 123).

Diante disso, nota-se que o patrimônio cultural brasileiro é formado por todos os meios de expressão, materiais ou imateriais, consistindo na memória da sociedade, incluindo-se os documentos. A Constituição atenta-se, ainda, para a importância da preservação dos bens patrimoniais brasileiros, conforme $\S 1^{\circ}$ do Art. 216:

O Poder Público, com a colaboração da comunidade, promoverá e protegerá o patrimônio cultural brasileiro, por meio de inventários, registros, vigilância, tombamento e desapropriação, e de outras formas de acautelamento e preservação (BRASIL, 1988, p. 123).

Tal como a administração pública, a comunidade tem a responsabilidade de proteger o patrimônio cultural, tendo em vista que a memória de todos é registrada e perpetuada em meio aos bens culturais, refletindo o conjunto de indivíduos da nação. Convém salientar, de acordo com Jardim (1995), que no século XIX o Estado percebe a importância de constituir um patrimônio cultural que the dê identidade. Portella (2012, p. 20) define patrimônio cultural como "elo entre o passado e o presente de um grupo ou de uma nação que permite a identificação e a continuidade de sua história". Pode-se, então, remeter este mesmo sentido à preservação do patrimônio documental (como patrimônio cultural), onde a ligação que a sociedade possui com as formas de registro de seu passado gera uma identidade, pois, por meio dos registros acessíveis, os indivíduos podem rememorar sua história. A esse respeito, Castro diz que:

A preservação [...] do patrimônio constituem-se (sic) como empreendimentos culturais direcionados a prolongar a vida útil dos objetos materiais e, assim, possibilitar a relação dialógica com estes 
bens culturais portadores de múltiplas significações (CASTRO, 2008, p. 12).

Com vistas a uma breve contextualização sobre o início da cultura de preservação documental, Silva (2010) descreve que foi a partir de 1966, quando ocorreu uma forte enchente do Rio Arno, em Florença, na Itália, que veio a degradar livros raros e documentos manuscritos existentes na região. O sinistro ocorrido no citado local serviu de exemplo mundial e motivou a criação de políticas de preservação de acervos, além de impulsionar o surgimento de novas técnicas.

Castro (2008, p. 49) menciona que, juntamente com especialistas e restauradores internacionais, havia "jovens voluntários que ficaram conhecidos como os gli angeli del fango (anjos da lama) em razão do espírito de luta, abnegação e responsabilidade cívica revelados na tarefa de salvação do patrimônio cultural". Castro (Ibid.) expõe que a Organização das Nações Unidas para a Ciência e Cultura (UNESCO) organizou a ação de recuperação com o intuito de salvar o patrimônio degradado. Desde então, surgiu uma preocupação, não somente dos profissionais e estudiosos em proteger os acervos, mas da própria sociedade, em manter e perpetuar a sua história.

O Dicionário Brasileiro de Terminologia Arquivística (ARQUIVO NACIONAL, 2005, p. 135) traz a seguinte definição para preservação: "Prevenção da deterioração e danos em documentos, por meio de adequado controle ambiental e/ou tratamento físico e/ou químico." A preservação documental é de extrema importância, pois visa a proteger os documentos de possíveis degradações que o acervo possa sofrer. Para que ocorra a preservação, é necessária a observação da ação dos vários agentes de degradação, que podem ser internos ou externos ao suporte em que se encontra a informação. Bellotto (2014) comenta que após o documento cumprir a função para a qual foi criado, será preservado para fins de pesquisas, testemunho e herança cultural. Cabe salientar que, independente da finalidade da guarda dos documentos, a preservação é imprescindível para manter o bom estado físico dos suportes, evitando assim a deterioração do patrimônio documental.

Atualmente, em meio à grande produção informacional, os arquivos vêm se desenvolvendo juntamente com a tecnologia, que permite cada vez mais produzir e difundir as informações. Para tanto, ações de cunho preventivo são práticas bem 
vindas nos arquivos, para que se preserve o patrimônio documental em longo prazo de maneira que a sociedade possa, sempre, rememorar sua história, por meio do acesso às informações contidas nos documentos.

\subsection{História e memória: uma relação latente com os arquivos}

A História é tudo o que nos rodeia sobre os acontecimentos passados. Assim como o presente e o futuro também serão história. Toda história, seja transmitida pela escrita, ou mesmo pela oralidade, ao ser interpretada permite ao sujeito algum tipo de subjetividade em sua interpretação.

Sobre as origens da palavra História, esta surge do grego antigo historie e apresenta vários sentidos, tais como: "ver", "procurar", "investigações" (LE GOFF, 2012, p. 20). O autor menciona que a História iniciou como sendo simples relatos, porém com sua evolução, se tornou muito mais, é considerada uma prática social, e nela uma importante característica se destaca, a de que cada acontecimento é único. A História é uma ciência que analisa e descreve como os fatos aconteceram, neste sentido, Le Goff (2012) defende que a história é "uma ciência da mutação e da explicação da mudança." (LE GOFF, 2012, p. 17).

De acordo com Silva e Lima (2009), é especifico da História se relacionar com o tempo. Este ponto de vista dos autores é bastante objetivo, pois um acontecimento não ocorre isolado; precisa ser situado, tanto no tempo quanto num lugar. Os acontecimentos ocorrem em meio a um conjunto de indivíduos e, devido à sua relevância, importância e/ou repercussão, se tornam memoráveis no contexto de determinado grupo. Le Goff (2012) defende que a História é a forma científica que assume a memória, pois há uma seleção de fatos ou elementos que se tornarão memória, no contexto de um determinado grupo. Ou seja, a seleção de fatos representa fragmentos de algo que seja considerado como simbólico por indivíduos que são parte daquele contexto.

Em se tratando de memória, Jardim (1995), considera que é um tema de estudo, tratado de maneira interdisciplinar, e defende que a memória, diferentemente da História, não se constitui de um conhecimento produzido de forma intencional; ela é a percepção do passado. Oliveira (2010) enfatiza que é um tema abordado por distintas áreas do conhecimento e imprescindível para as que utilizam, também, os registros de informação. A autora chama atenção para as possibilidades de uso 
conceitual, de acordo com a abordagem e viés que se deseja adotar. Desta forma, sendo o conceito de memória amplo e variável cabe destacar que neste estudo utiliza-se do seu conceito no sentido da representação de algo memorável; ou, mais especificamente, na relação que esta possui com a História (proveniente das ações do quotidiano, registradas) e com os documentos (meio formal de registro). A memória é voltada à representatividade de fatos passados aos quais são atribuídos significados pela sociedade.

Sobre a memória, Lodolini evidencia a necessidade que o homem trouxe consigo, desde os primórdios, de preservá-la, registrando suas atividades

[...] desde a mais alta Antigüidade, o homem demonstrou a necessidade de conservar sua própria "memória" inicialmente sob a forma oral, depois sob a forma de graffiti e desenhos e, enfim, graças a um sistema codificado... A memória assim registrada e conservada constituiu e constitui ainda a base de toda atividade humana: a existência de um grupo social seria impossível sem o registro da memória, ou seja, sem os arquivos (LODOLINI, 1990 apud JARDIM, 1995, p. 4).

Sob o ponto de vista de Pereira, a memória é

[...] a capacidade de adquirir, armazenar e recuperar informações disponíveis tanto no cérebro como em outros mecanismos artificiais como, por exemplo (sic) a memória de um computador, ou nos documentos de arquivo. [...] É através dela que damos significado ao cotidiano (PEREIRA, 2011, p. 23).

Sucintamente compreende-se que a memória é representada por meio de registros de informação, qualquer que seja o suporte em que está contida e que seja passível de recuperação (acesso); aos fatos ou às ações registradas se atribui um significado o qual constitui a memória desses acontecimentos. De acordo com Pereira "A construção da memória está estreitamente vinculada ao acesso à informação, que por sua vez está vinculada à organização dos seus suportes materiais." (PEREIRA, 2011, p. 20). Assim, a autora ressalta que a construção da memória se correlaciona fortemente ao acesso à informação, neste sentido, entende-se que o acesso à informação é a base para a construção da memória e, destaca ainda sobre a relação do acesso à organização dos suportes. $O$ acesso se torna moroso ou inexistente quando os registros informacionais não estão 
ordenados, o que dificulta sua acessibilidade. Assim, a História acontece nas ações diárias independente do sujeito da execução, seja uma organização ou um indivíduo.

Atualmente, as ações formais são gravadas ou escritas em unidades de registro, em diversos tipos de suportes existentes, aos quais podem ser chamados de documentos; esses registros são considerados formas de memória que contam a História humana. Desse modo, Barros e Amélia afirmam que a memória registrada "delegou ao arquivo a função de mantê-la viva, de forma a desacelerar o desparecimento de sinais do que se deseja manter, em face da necessidade do lembrar." (BARROS; AMÉLIA, 2009, p. 57). Diante disso, em se tratando de memória registrada, é importante considerar sua preservação para possibilitar o acesso, tendo em vista que o armazenamento dos documentos nos arquivos tem, dentre outros, o intuito de preservá-los em razão de seu valor histórico que representa para a sociedade. Enfoca-se, aí, uma importante relação entre a História e a memória, quase indissolúvel, pois o enlace desses elementos, em meio aos seus registros, reforça a ideia de que a História e a memória estão ligadas aos documentos, nos mais variados tipos de suportes, de onde é possível que a sociedade tenha acesso à História e possam recorrer às memórias escritas nas fontes formais e autênticas de informações. Moreira (2005, p. 1) manifesta que "A Memória, no sentido primeiro da expressão, é a presença do passado." E que "A memória é uma construção psíquica e intelectual que acarreta de fato uma representação seletiva do passado, que nunca é somente aquela do indivíduo, mas de um indivíduo inserido num contexto" (MOREIRA, 2005, p. 1).

Sobre os arquivos, Pereira (2011, p. 24) assim reflete: "Visto que os documentos são uma forma de expressão da memória, então os arquivos são os detentores da memória individual e coletiva, servindo de suporte para a constituição da história das instituições e da identidade de um determinado povo.". Nesta mesma perspectiva, Silva e Lima (2009) comentam que os escritos serviam de suporte à memória e que os arquivos surgiram para conservá-los. Portanto, os documentos arquivísticos são a própria construção de uma memória social de um determinado grupo de indivíduos, pode-se dizer então, que a memória da sociedade, registrada nos documentos de arquivo formam um patrimônio documental.

Pavezi (2010) comenta que a UNESCO, em 1992 instituiu o Programa Memória do Mundo visando a proteger o patrimônio cultural mundial. O Brasil, em 
2004, aderiu ao programa, criando o Comitê Nacional do Brasil do Programa Memória do Mundo da UNESCO, com a finalidade de "assegurar a preservação das coleções documentais" para, então "democratizar o seu acesso e criar a consciência sobre sua importância e a necessidade de preservá-lo" (PAVEZI, 2010, p. 28). Tal iniciativa possibilita aos cidadãos observar uma valorização das fontes informacionais neste país, dando vistas à relevância das coleções de documentos, bem como demonstra a importância de sua preservação, em âmbito nacional.

Nesta perspectiva, é possível compreender que os arquivos possuem uma ligação com a História e a memória, por meio de fatos registrados, ou seja, por meio dos documentos arquivísticos. Esta importante relação evoca aos cidadãos a busca por memórias passadas, e instiga ao resgate de sua identidade. Assim, em meio a esta contextualização, a sociedade pode ser considerada como o eixo dessa relação, pelas razões, também, apresentadas a seguir.

\subsection{A sociedade $\mathrm{e} 0$ acesso à informação: um direito}

Os documentos consistem em fontes de informação; face a isso, é importante destacar que são passíveis de acesso. Visto anteriormente que é dever da administração pública proteger os documentos de arquivo, cumpre contextualizar que:

O Estado atua em nome da sociedade e, consequentemente, não é proprietário, mas guardião do bem público. E assim também ocorre com a informação que é produzida e custodiada pelo Estado, que na essência é um bem público e pertence à sociedade, visto que é produzida para gerar resultados a ela destinados. (CGU, 2014, p. 7).

A Constituição Federal situa os documentos como parte do patrimônio cultural brasileiro; neste sentido, pode-se entender o patrimônio documental como um capital da sociedade, de que o Estado possui a guarda. $O$ acesso à informação é um direito adquirido pela sociedade brasileira, assegurado por meio da Carta Magna, conforme o art. 5으, inciso XIV (BRASIL, 1988). Rueda, Freitas e Valls consideram que:

Fatores como o fim da ditadura, o processo de redemocratização, a promulgação da Constituição de 1988 e o início do acesso às revoluções tecnológicas, (sic) abriram a possibilidade de resgatar informações, para se conhecer a história do país e disponibilizar 
essas informações de forma organizada e transparente à sociedade (RUEDA, FREITAS E VALLS, 2011, p. 85).

Ainda assim, por muito tempo, o direito constitucional de acesso à informação no Brasil foi ignorado pelo próprio Estado; porém, sinais de transparência começaram a ser observados com a criação de leis precursoras à recente Lei de Acesso à Informação (LAI). A Lei, sancionada no dia 18 de novembro de 2011, sob no 12.527, tornou-se um marco na história da sociedade da informação, a qual, cada vez mais, aumenta sua necessidade informacional. Esta lei proporciona a todos os cidadãos a regulamentação do acesso às informações da esfera pública, podendo ser de seu próprio interesse, ou de interesse coletivo (BRASIL, 1988).

A sociedade carecia de um amparo legal regulatório, desde que o acesso foi previsto na Constituição Federal de 1988 e, conforme o art. $216 \S 2^{\circ}$, "Cabem à administração pública, na forma da lei, a gestão da documentação governamental e as providências para franquear sua consulta a quantos dela necessitem." (BRASIL, 1988, p. 123). Sendo assegurado o direito, a lei de acesso o regulamentou. Concomitantemente, o poder público necessitou realizar adequações internas, no âmbito dos órgãos governamentais, para que pudesse atender às demandas informacionais, sob o prazo legal de resposta aos solicitantes (BRASIL, 2011).

A Lei 8159/1991 reafirma, no art. 4ํㅡ o direito de todo cidadão em obter informações de interesse pessoal ou coletivo, dos órgãos governamentais, constantes nos documentos de arquivo (BRASIL, 1991). Porém, muitas vezes o direito fundamental estabelecido na legislação brasileira recai na ausência ou inconsistência de políticas públicas arquivísticas. A este respeito, Sousa argumenta que:

(...) podemos, sim, falar de políticas públicas de arquivo, pois ela carrega a defesa e a garantia de direitos individuais e coletivos. A importância e o valor estratégico da informação arquivística para a sociedade brasileira, como para qualquer outra sociedade, justifica a necessidade da formulação de políticas públicas de arquivo no país (SOUSA, 2006, p. 4).

Não sendo uma política de arquivos, mas de acessibilidade à informação, a LAl regulamentou o direito de acesso, incluindo prazo para a administração pública responder aos pedidos formalizados (BRASIL, 2011). Contudo, esse direito estará 
assegurado se a informação for organizada e preservada para possibilitar sua acessibilidade.

Para que os cidadãos obtenham acesso é essencial, primeiramente, que conheçam seus direitos. Mesmo se sua necessidade de informação esteja contida em um documento classificado como sigiloso, ainda é possível recorrer ao Estado para que tal informação seja desclassificada (BRASIL, 2011). Em suma, após o órgão que receber o pedido de recurso e proceder à análise, tal informação pode se tornar ostensiva, ou seja, torna a informação pública e a divulgação das informações não irá ferir a segurança da sociedade ou do Estado (conforme especificação do art. 23, da Lei). Deste modo, além de garantir o acesso às informações públicas, a LAI ainda tem por finalidade resguardar os documentos de caráter sigiloso, cuja restrição seja indispensável para a proteção do Estado e dos indivíduos (BRASIL, 2011). Assim como o acesso beneficia os indivíduos, o sigilo, conforme os casos específicos mencionados na lei de acesso, também se torna imprescindível para a segurança e ordem da Nação.

É oportuno dizer que a possibilidade de acesso aos documentos públicos, proporcionada a partir da LAl, é um importante recurso ao pleno exercício do direito constitucional de acesso, o qual contribui para a sociedade brasileira tomar conhecimento de sua História.

\section{CONSIDERAÇÕES FINAIS}

A definição dos documentos como bem patrimonial cultural pela Constituição Federal de 1988 favoreceu o olhar sobre o patrimônio documental do país e sua preservação. Isto posto, evidencia-se que o Estado necessita manter o compromisso constitucional de acesso às informações consideradas de caráter público, agora regulamentado pela criação de uma lei específica - a lei de acesso à informação mas também tem o dever de ser cauteloso com informações classificadas como sigilosas.

A História e a memória são acessíveis e podem ser acessadas por meio dos documentos de arquivo. Neste sentido, o presente estudo buscou salientar a relação documentos, história e memória, identificando a importância da preservação do patrimônio documental, visando ao acesso à informação. 
Mas por que é preciso preservar o patrimônio documental? No diálogo exposto, é perceptível a "construção" da História, por meio dos conjuntos de documentos armazenados nos arquivos, que se tornam a memória da sociedade. $\mathrm{E}$, sendo a sociedade detentora do direito de acesso à informação, assegurado pela Constituição Federal do Brasil, cabe à administração pública gerir e preservar o patrimônio documental para que, no momento em que os cidadãos requisitarem informações de interesse pessoal ou coletivo, estas sejam disponibilizadas.

Acredita-se na possibilidade deste estudo contribuir com futuras pesquisas acerca do tema proposto. Entende-se que são necessárias mais discussões voltadas à temática aqui apresentada, de forma que se busque a construção desta relação, estreitando os laços invisíveis entre o documento, a História e a memória com a sociedade.

\section{REFERÊNCIAS}

ARQUIVO NACIONAL (BRASIL). Dicionário Brasileiro de Terminologia Arquivística. Rio de Janeiro: Arquivo Nacional, 2005.

Gestão de documentos: curso de capacitação para os integrantes do Sistema de Gestão de Documentos de Arquivo - SIGA, da administração pública federal. Rio de Janeiro: Arquivo Nacional, 2011.

BARROS, Dirlene Santos; AMÉLIA, Dulce. Arquivo e memória: uma relação indissociável. TransInformação. Campinas, 2009. Disponível em:

$<$ http://periodicos.puc-

campinas.edu.br/seer/index.php/transinfo/article/view/518/498>. Acesso em: 28 jan. 2015.

BELLOTTO, Heloisa Liberalli. Arquivos permanentes: tratamento documental. 4. ed. Rio de Janeiro: Ed. FGV, 2006.

BELLOTTO, Heloisa Liberalli. Arquivos: estudos e reflexões. Belo horizonte: Editora UFMG, 2014.

BRASIL. Constituição (1988). Constituição da República Federativa do Brasil. Disponível em: < http://www.planalto.gov.br/ccivil_03/constituicao/constituicao.htm>. Acesso em: 06 jun. 2014.

. Lei 8.159 de 08 de janeiro de 1991. Dispõe sobre a política nacional de arquivos públicos e privados e dá outras providências. Disponível em:

<http://www.planalto.gov.br/ccivil_03/leis/L8159.htm>. Acesso em: 30 mai. 2014. 
Lei 12.527, de 18 de novembro de 2011. Regula o acesso às informações. Disponível em: <http://www.planalto.gov.br/ccivil_03/_ato20112014/2011/lei//12527.htm>. Acesso em: 28 mai. 2014.

CASTRO, Aloisio Arnaldo Nunes de. A trajetória histórica da conservaçãorestauração de acervos em papel no brasil. Dissertação de Mestrado em História. UFJF, 2008. Disponível em: $<$ http://www.ufjf.br/ppghistoria/files/2009/12/Aloisio_A_N_de_Castro1.pdf>. Acesso em: 02 jun. 2014.

CGU, Controladoria Geral da União. Rumo a uma cultura de acesso à informação: a Lei 12.527/2011. Módulo I. Brasília, 2014. Disponível em: $<$ https://escolavirtual.cgu.gov.br/ead/course/view.php?id=283>. Acesso em: 12 jun. 2014.

INDOLFO, Ana Celeste. Gestão de documentos: uma renovação epistemológica no universo da Arquivologia. Arquivística.net. v. 3, n. 2, 2007. Disponível em: <http://www.brapci.ufpr.br/download.php?dd0=3553>. Acesso em: 08 maio 2014.

JARDIM, José Maria. A invenção da memória nos arquivos públicos. Revista Ciência da Informação, Brasília, v. 25, n. 2, 1995. Disponível em: <http://revista.ibict.br/ciinf/index.php/ciinf/article/viewFile/439/397>. Acesso em: 12 mai. 2014.

MOREIRA, Raimundo Nonato Pereira. História e memória: algumas observações. 2005. Disponível em: <http://pablo.deassis.net.br/wpcontent/uploads/Hist\%C3\%B3ria-e-Mem\%C3\%B3ria.pdf>. Acesso em: 20 jun. 2014.

OLIVEIRA, Eliane Braga de. O conceito de memória na Ciência da Informação no Brasil: uma análise da produção científica dos programas de pós-graduação. (Tese de doutorado). Programa de Pós-Graduação em Ciência da Informação/Universidade de Brasília. Brasília, 2010. Disponível em: <http://repositorio.unb.br/bitstream/10482/7466/1/2010_ElianeBragaOliveira.pdf>. Acesso em: 05 fev. 2015.

PAES, Marilena Leite. Arquivo: teoria e prática. Rio de Janeiro: FGV, 2007.

PAVEZI, Neiva. Arquivo fotográfico: uma faceta do patrimônio cultural da UFSM. (Dissertação de mestrado). Programa de Pós-Graduação Profissional em Patrimônio Cultural/Universidade Federal de Santa Maria. Santa Maria, 2010. Disponível em: $<$ http://cascavel.cpd.ufsm.br/tede/tde_busca/arquivo.php?codArquivo=2956>. Acesso em: 12 jun. 2014.

PEREIRA, Fernanda Cheiran. Arquivos, memória e justiça: Gestão documental e preservação de acervos judiciais no Rio Grande do Sul. Disponível em: <http://www.lume.ufrgs.br/handle/10183/31152>. Acesso em: 12 mai. 2014. 
PORTELLA, Viviane Portella de. Difusão virtual do patrimônio documental do Arquivo Público do Estado do Rio Grande do Sul. Dissertação de mestrado, PPGPPC/UFSM, 2012. Disponível em:

<http://www.apers.rs.gov.br/arquivos/1360344101.6_Dissertacao_versao_final.pdf>. Acesso em: 20 jun. 2014.

RICHTER, Eneida Izabel Schirmer; GARCIA, Olga Maria Correa; PENNA, Elenita Freitas. Introdução à arquivologia. 2. ed. Santa Maria: FACOS-UFSM, 2004.

RUEDA, Valéria Matias da Silva; FREITAS, Aline de; VALLS, Valéria Martin. Memória Institucional: uma revisão de literatura. CRB-8 Digital, São Paulo, v.4, n. 1, 2011. Disponível em:

<http://revista.crb8.org.br/index.php/crb8digital/article/viewFile/62/64>. Acesso em: 11 jun. 2014.

SCHELLENBERG, Theodore Roosevelt. Arquivos modernos: princípios e técnicas. Rio de Janeiro: FGV, 2006.

SILVA, Beatriz Aita da. Gestão e preservação da informação. Apostila da Disciplina de Gestão e preservação da informação, Especialização Gestão em Arquivos. Santa Maria: UFSM, 2010.

SILVA, Edna Lúcia da; MENEZES, Estera Muzskat. Metodologia da pesquisa e elaboração de dissertação. 4. ed. rev. atual. Florianópolis: UFSC, 2005.

SILVA, Ligiane Aparecida da; LIMA, Rosilene de. Jacques Le Goff: Estudo de conceitos em história da educação. In: IX Congresso Nacional de Educação. 2009. Disponível em:

<http://www.pucpr.br/eventos/educere/educere2009/anais/pdf/3122_1893.pdf>. Acesso em: 21 mai. 2014.

SOUSA, Renato Tarciso Barbosa de. $\mathrm{O}$ arquivista e as políticas públicas de arquivo. In: II Congresso Nacional de Arquivologia. Anais... Porto Alegre: ABARQ-UnB, 2006.

Title

Document history and memory: the importance of the documentary heritage preservation for access to information

\section{Abstract}

Introduction: The story is recorded in documents that form a set, the documentary heritage. Objective: This study aims to identify the importance of preserving the documentary heritage through the relationship document, history and memory, in order to access to information.

Methodology: From the point of view of the methodological procedures used, it is a literature search. So was delimited using material published book, journal, or internet. 

para o acesso à informação

Results: In Brazil, the Federal Constitution of 1988 defined the public documents as cultural heritage of the country. This heritage is the memory of society, so it is necessary to preserve it for Brazilian citizens can access it when needed. The right of access provided for constitutionally, was regulated by the Law on Access to Information.

Conclusions: access law is considered a milestone in Brazilian society to exercise their rights. The purpose of the preservation of documentary heritage is to enable citizens, the memory access to build their identity. The relationship document history and memory is rarely addressed by Brazilian researchers, from the point of view of the need to preserve the documentary heritage of society aiming at the right of access to information. Thus, stirs up a bigger split on the topic presented.

Key words: Document. History. Memory. Documentary Heritage. Information Access.

\section{Título}

Documento, historia y memoria: la importancia de la preservación del patrimonio documental para el acceso a la información

\section{Resumen}

Introducción: La historia está registrada en los documentos que forman un conjunto, el patrimonio documental.

Objetivo: Este estudio tiene como objetivo identificar la importancia de preservar el patrimonio documental a través del la relación documento, historia y memoria, con el fin de acceder a la información.

Metodología: Desde el punto de vista de los procedimientos metodológicos utilizados, se trata de una búsqueda en la literatura. Así fue delimitado con material publicado libro, revista, o internet.

Resultados: En Brasil, la Constitución Federal de 1988 definió los documentos públicos como patrimonio cultural del país. Esta herencia es la memoria de la sociedad, por lo que es necesario preservarlo para los ciudadanos brasileños puedan acceder a ella cuando sea necesario. El derecho de acceso previsto por la Constitución, se regula por la Ley de Acceso a la Información.

Conclusiones: La ley de acceso se considera un hito en la sociedad brasileña a ejercer sus derechos. El propósito de la preservación del patrimonio documental es permitir a los ciudadanos, el acceso a la memoria para construir su identidad. La relación de la historia, los documentos y la memoria es raramente abordados por investigadores brasileños, desde el punto de vista de la necesidad de preservar el patrimonio documental de la sociedad con el objetivo del derecho de acceso a la información. Por lo tanto, suscita más estudio en el tema presentado.

Palabras clave: Documento. Historia. Memoria. Patrimonio documental. Acceso a la información.

Recebido em: 16.09.2014

Aceito em: 22.03.2015

Inf. Inf., Londrina, v. 20, n. 1, p. 26 - 42, jan./abr. 2015.

http:www.uel.br/revistas/informacao/ 